\title{
Coupled heat and moisture transfer features of typical external thermal insulation systems
}

\author{
Yang Wang ${ }^{1 *}$, Xiaoyu $\mathrm{Hu}^{2}$, Shiyong $\mathrm{Wu}^{1}$ \\ ${ }^{1}$ Department of Building Engineering, Hefei University, Hefei 230601, China \\ ${ }^{2}$ School of Management, Jinan University, Guangzhou 510632, China
}

Corresponding Author Email: 122432892@qq.com

https://doi.org/10.18280/ijht.360427

Received: 2 March 2018

Accepted: 10 July 2018

\author{
Keywords: \\ external thermal insulation (ETI), \\ exterior wall, moisture content, coupled \\ heat and moisture, thermal insulation \\ effect.
}

\begin{abstract}
Targeting three typical external thermal insulation systems, this paper puts forward a new principle (change of capacitive reactance of high-frequency electromagnetic wave sensors) for measuring the temperature and humidity in the interface between different layers of exterior walls. Following this method, several other ways such as thermal calculations, software simulations and model analyses are compared with each other to evaluate the actual thermal insulation and heat transfer effects of the walls, discuss the causes of thermal insulation defects and the solutions to remedy these defects. The research findings provide a valuable reference for the design, construction, application, evaluation and repair of energy-saving walls in hot summer and cold winter areas.
\end{abstract}

\section{INTRODUCTION}

The external thermal insulation composite systems (ETICS) have been popularized in the hot summer and cold winter regions of China. However, the system fails to achieve a desirable effect, as the building envelope structure, stuck between the unsteady outdoor climate and the stable indoor climate, is subjected to temperature and pressure gradients. Under these gradients, the water vapor migrates in the moisture absorption zone while the liquid water transfers in the capillary zone of the building envelope. The internal moisture transport is exacerbated by the moisture absorption and leakage on the wall surface, which are resulted from the porous structure of the thermal insulation material and construction defects. These moisture-related actions severely affect the insulation effect and the durability of the ETI structure, pushing up the building maintenance cost [1].

The building group in our research uses three ETI systems widely applied for thin-plastered exterior wall. For the material of the insulation layer, the three systems respectively adopt rubber powder polystyrene particles (RPPPs), glazed hollow bead insulation mortar (GHBIM) and rock wool board (RWB). In some buildings, the ETI systems suffer from severe hollowing, moisture absorption and spalling, posing great safety hazards. The damages are particularly serious in the ETI system using GHBIM as the insulation layer material. Although the ETI systems have been used for no more than 8 years, public bidding is being planned to rework the ETICS, the budget is as high as RMB 20 million yuan.

The existing studies on the thermal and humid environment of buildings rarely consider the moisture migration of the envelope structure [2], owing to the difficulty in exploring the thermal mass transfer of porous media. However, the effect of humidity on thermal insulation performance must be taken into account to accurately evaluate the service of thermal insulation systems [3].

Considering the above, this paper puts forward the following technical solution: (1) Initially identification of the structural and hygroscopic defects of ETICS through the scanning with an infrared thermal imager; (2) Determining the actual moisture and heat transfer conditions after collecting the temperature, humidity, dew point, water content, and water absorption distribution in typical parts of the walls with sensors; (3) Software simulation and calculation of theoretical heat transfer and moisture migration according to the measured environmental parameters and energy-saving design parameters.

The resulting theoretical, measured, simulated and analytical values were subjected to multi-dimensional analysis and cross-validation, with the aim to evaluate the actual effect of the ETICS.

\section{EXPERIMENTAL DESIGN AND PROCEDURE}

Several field tests were performed on the three ETICS of thin-plastered, capturing the variations in indices like the internal temperature field and moisture content. Then, the coupling between the temperature and humidity were analyzed based on the test data.

The thermal conductivity coefficient and other thermal parameters were extracted from the energy-saving design data in the design drawings (Table 1). For coal gangue sintered hollow brick, the air interlayer was neglected in the heat transfer calculation. The heat resistance refers to the comprehensive thermal resistance. If the actual thickness deviates from the designed thickness, the actual thickness should prevail.

The leakage areas were first detected by an FLIR B360 infrared thermal imager, and the subsequent temperature and moisture measurements were carried out around these typical areas. The detection philosophy is as follows: Leakage takes place easily after the failure of the waterproof layer on the wall surface; in this case, the dampness may penetrate into the thermal insulation layer, which is porous and easy to absorb water. Due to the large thermal conductivity and heat capacity 
of water, the temperature distribution on the surface of defected parts will differ greatly from that on the surface of normal parts. This difference can be pinpointed by the infrared thermal image [4]. As shown in Figure 1, the exterior walls with Type RPPPs and Type GHBIM were subjected to different degrees of water intrusion (Figures 1a and 1b), while the exterior wall with Type RWB was basically not intruded by external moisture (Figure 1c).

Table 1. Structure and related thermal parameters of the three ETICS

\begin{tabular}{|c|c|c|c|c|c|}
\hline $\begin{array}{l}\text { 1.1.1. Type of } \\
\text { ETICS }\end{array}$ & $\begin{array}{l}\text { 1.1.2. Wall structure } \\
\text { (from the outside to the } \\
\text { inside) }\end{array}$ & $\begin{array}{c}\text { 1.1.3. Actual } \\
\text { thickness }(\mathrm{mm})\end{array}$ & $\begin{array}{c}\text { 1.1.4. Thermal } \\
\text { conductivity coefficient } \\
\mathrm{W} /\left(\mathrm{m}^{2} \cdot \mathrm{K}\right)\end{array}$ & $\begin{array}{l}\text { 1.1.5. Heat storage } \\
\text { coefficient W/( } \mathrm{m}^{2} \bullet \\
\mathrm{K})\end{array}$ & $\begin{array}{l}\text { 1.1.6. Thermal } \\
\text { resistance }\left(\mathrm{m}^{2} \bullet\right. \\
\mathrm{K}) / \mathrm{W}\end{array}$ \\
\hline \multirow{4}{*}{$\begin{array}{l}\text { 1.1.7. Type } \\
\text { RPPPs }\end{array}$} & 1.1.8. Anti-crack mortar & 1.1 .9 .5 & 1.1 .10 .0 .93 & 1.1 .11 .11 .27 & 1.1 .12 .0 .005 \\
\hline & 1.1.13. RPPPs & 1.1.14. 20 & 1.1.15. 0.06 & 1.1.16. 1.02 & 1.1.17. 0.43 \\
\hline & $\begin{array}{l}\text { 1.1.18. Clay sintered } \\
\text { hollow brick }\end{array}$ & 1.1.19. 200 & 1.1 .20 .0 .58 & 1.1 .21 .7 .85 & 1.1.22. 0.34 \\
\hline & 1.1.23. Lime mortar & 1.1.24. 20 & 1.1.25. 0.87 & 1.1.26. 10.75 & 1.1 .27 .0 .02 \\
\hline \multirow{4}{*}{$\begin{array}{l}\text { 1.1.28. Type } \\
\text { GHBIM }\end{array}$} & 1.1.29. Anti-crack mortar & 1.1 .30 .5 & 1.1 .31 .0 .93 & 1.1 .32 .11 .306 & 1.1.33. 0.009 \\
\hline & 1.1.34. GHBIM & 1.1 .35 .40 & 1.1.36. 0.08 & 1.1.37. 0.900 & 1.1.38. 0.497 \\
\hline & $\begin{array}{l}\text { 1.1.39. Coal gangue } \\
\text { sintered hollow brick }\end{array}$ & 1.1 .40 .200 & 1.1.41. 0.58 & 1.1.42. 9.05 & 1.1.43. 0.345 \\
\hline & $\begin{array}{l}\text { 1.1.44. Lime cement } \\
\text { mortar }\end{array}$ & 1.1 .45 .20 & 1.1.46. 0.93 & 1.1.47. 11.37 & 1.1.48. 0.009 \\
\hline \multirow{4}{*}{$\begin{array}{l}\text { 1.1.49. Type } \\
\text { RWB }\end{array}$} & $\begin{array}{l}\text { 1.1.50. Crack resistant } \\
\text { mortar }\end{array}$ & 1.1 .51 .5 & 1.1.52. 0.93 & 1.1 .53 .11 .37 & 1.1.54. 0.005 \\
\hline & 1.1.55. RWB & 1.1 .56 .50 & 1.1.57. 0.045 & 1.1.58. 0.75 & 1.1.59. 1.204 \\
\hline & $\begin{array}{l}\text { 1.1.60. Coal gangue } \\
\text { sintered hollow brick }\end{array}$ & 1.1.61. 200 & 1.1.62. 0.58 & 1.1.63. 7.92 & 1.1.64. 0.345 \\
\hline & $\begin{array}{l}\text { 1.1.65. Lime cement } \\
\text { mortar }\end{array}$ & 1.1.66. 20 & 1.1.67. 0.93 & 1.1 .68 .11 .37 & 1.1.69. 0.022 \\
\hline
\end{tabular}
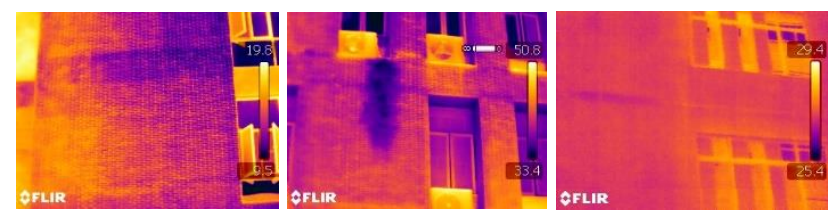

(a) Facade of Type (b) facade of Type (c) facade of Type RPPPs GHBIM

RWB

Figure 1. Thermal images for typical areas of three different ETICS

The temperature measurement was relatively simple. Several NiCr-Ni thermocouple sensors were pasted between the wall structure layer and the insulation layer, and connected to an Ahlborn MU-56901 desktop data acquisition instrument. In this way, the temperature data could be obtained automatically at regular intervals. The real-time temperatures obtained from the positions of the sensors were automatically saved into the laptop (Figure 2a).

The temperature measuring points were arranged as follows. In view of the small size of NiCr-Ni thermocouples (diameter: $0.5 \mathrm{~mm}$ ), the sensors were placed through drilled holes (or prewired) at the interface between the wall structure layer (either clay sintered hollow brick or coal gangue sintered hollow brick) and the insulation layer and that between the insulation layer and the crack resistant mortar layer. The temperature sensing end was wrapped up with plasticine to ensure the contact-type temperature measurement, while the pores and fissures were sealed up with glass glue to prevent moisture entry and eliminate environmental impact.

The inner and outer surface temperatures of the walls were measured accurately and conveniently by a Raytheon infrared spot thermometer. An ALBORN-2908 handheld data collector was connected to FHA646 sensors to capture the ambient temperature and humidity indoor and outdoor, and to FHA6X6 sensors to measure the relative humidity of the internal air layer and the relative humidity in the cavity of hollow bricks (Figure 2b).

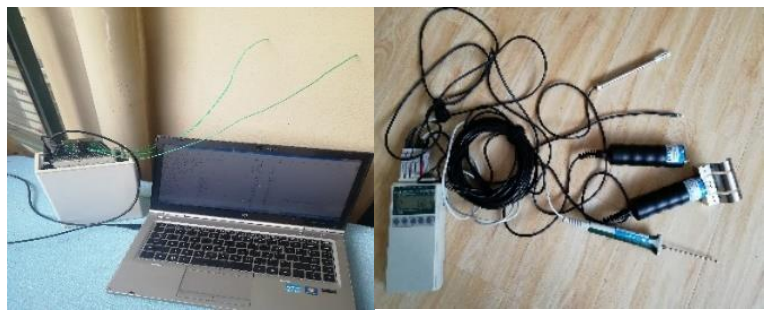

(a) Ahlborn MU-56901

(b) ALBORN-2908

Figure 2. Thermal and moisture measurement devices

The measurement of moisture content is a key difficulty in the experimental research of thermal and moisture coupling of walls [5]. The existing testing methods are not unified or mature enough [6]. The water content is generally derived from the functional relationship between the relative humidity and moisture content of the material surface [7-9]. However, this approach is not easy to implement, and cannot output accuracy results for the thermal insulation materials of our experiment.

In our experiment, the ALBORN-2908 handheld data collector was connected to FHA696-MF sensors (Figure 2b). Then, the built-in high-frequency electromagnetic wave probe was pressed against the thermal insulation materials. Since the dielectric constant varies with the water contents in these materials, the moisture content was obtained according to the changes of the capacitive reactance of the probe. In the initial calibration experiment, the offset compensation amount was set to 3.0 according to the type of insulation materials. The test depth of the probe is $25 \mathrm{~mm}$, the objects are thin-plastered exterior walls, the total thickness of the exterior facing layer and the crack resistant mortar layer is about $5 \mathrm{~mm}$, and the insulation layer to be tested is up to $20 \mathrm{~mm}$. Thus, our approach 
to measure moisture content can basically capture the overall trend of the moisture content of the insulation layer and satisfy the test requirements.

It is worth mentioning that the ALMEMO FH A696-MF can measure the moisture content in the range of $0 \sim 20 \%$ for building materials. Here, an MD288 wood moisture meter, which has a similar detection philosophy, was adopted for a comparison test. The test depth was $50 \mathrm{~mm}$, and the offset compensation amount was set to 5.0 for greater-than-20\% moisture content. Then, an auxiliary test was carried out on ALMEMO FHA936-WD. During the test, the probe electrode was inserted into the material, and the moisture content was determined based on the difference in output resistance (the resistance varies with the conductivity, which in turn changes with the moisture content of the material). In spite of its accuracy, this test method is not convenient, and was treated as an auxiliary method when the moisture content surpassed $20 \%$.

Through the above comparison and correction, the measured moisture content was relatively accurate and could reflect the actual trends.

\section{CALCULATION AND ANALYSIS OF EXPERIMENTAL RESULTS}

\subsection{Inspection of wall condensation}

The internal condensation of the envelope structure is very dangerous and easy to occur. Hence, the three ETICS were inspected carefully when the indoor air conditioner was turned on and turned off. No internal condensation was observed in any of the systems, which fully reveals the advantages of ETI structure. Below is the calculation process of Type GHBIM in Table 1:

After looking up the table, it was calculated that $\mathrm{R}_{0}=0.743$ $\mathrm{m}^{2} \cdot \mathrm{K} / \mathrm{W}$ and the wall's resistance to vapor permeability $\mathrm{H}_{0}=2,891.03 \mathrm{~m}^{2} \cdot \mathrm{h} \cdot \mathrm{Pa} / \mathrm{g}$.

The relative humidity of the indoor and outdoor environments was measured as $44 \%$ and $61 \%$, respectively.

The partial pressures of water vapor in indoor and outdoor airs were calculated as:

Since $\mathrm{t}_{\mathrm{i}}=21.95^{\circ} \mathrm{C}$ and $\mathrm{Ps}=2,634.4 \mathrm{~Pa}$, we have $\mathrm{P}_{\mathrm{i}}=2634.4 * 44 \%=1,159.1 \mathrm{~Pa}$

Since $\mathrm{t}_{\mathrm{e}}=8.48^{\circ} \mathrm{C}$ and $\mathrm{Ps}_{\mathrm{s}}=1,109.2 \mathrm{~Pa}$, we have $\mathrm{P}_{\mathrm{e}}=1,109.2 * 61 \%=676.6 \mathrm{~Pa}$

The partial pressure of water vapor $\mathrm{P}$ between the layers inside the envelope and the corresponding partial pressure of saturated water vapor $\mathrm{P}_{\mathrm{S}}$ were determined as:

$\mathrm{P}_{1}=\mathrm{P}_{\mathrm{i}}=1,159.1 \mathrm{~Pa}, \mathrm{P}_{1 \mathrm{~s}}=\mathrm{P}_{\text {is }}=2,410.5 \mathrm{~Pa}$;

$\mathrm{P}_{2}=\mathrm{P}_{\mathrm{i}}-\left(\mathrm{P}_{\mathrm{i}}-\mathrm{P}_{\mathrm{e}}\right) \mathrm{H}_{1} / \mathrm{H}_{0}=1,089.9 \mathrm{~Pa}, \mathrm{P}_{2 \mathrm{~s}}=2,366.5 \mathrm{~Pa}$;

$\mathrm{P}_{3}=\mathrm{P}_{\mathrm{i}}-\left(\mathrm{P}_{\mathrm{i}}-\mathrm{P}_{\mathrm{e}}\right)\left(\mathrm{H}_{1}+\mathrm{H}_{2}\right) / \mathrm{H}_{0}=797.9 \mathrm{~Pa}, \mathrm{P}_{3 \mathrm{~s}}=1,777.2 \mathrm{~Pa}$;

$\mathrm{P}_{4}=\mathrm{P}_{\mathrm{i}}-\left(\mathrm{P}_{\mathrm{i}}-\mathrm{P}_{\mathrm{e}}\right)\left(\mathrm{H}_{1}+\mathrm{H}_{2}+\mathrm{H}_{3}\right) / \mathrm{H}_{0}=735.0 \mathrm{~Pa}, \mathrm{P}_{4 \mathrm{~s}}=1,155.9 \mathrm{~Pa}$;

$\mathrm{P}_{5}=\mathrm{P}_{\mathrm{e}}=676.6 \mathrm{~Pa}, \mathrm{P}_{5 \mathrm{~s}}=\mathrm{P}_{\mathrm{es}}=1,147.9 \mathrm{~Pa}$.

The $\mathrm{P}$ and $\mathrm{Ps}$ distribution lines drawn from the above calculated results did not intersect each other (Figure 3), revealing that no condensation took place inside the walls. This means the wall surface seepage; insulation layer dampness and the high internal moisture content are attributable to external causes.

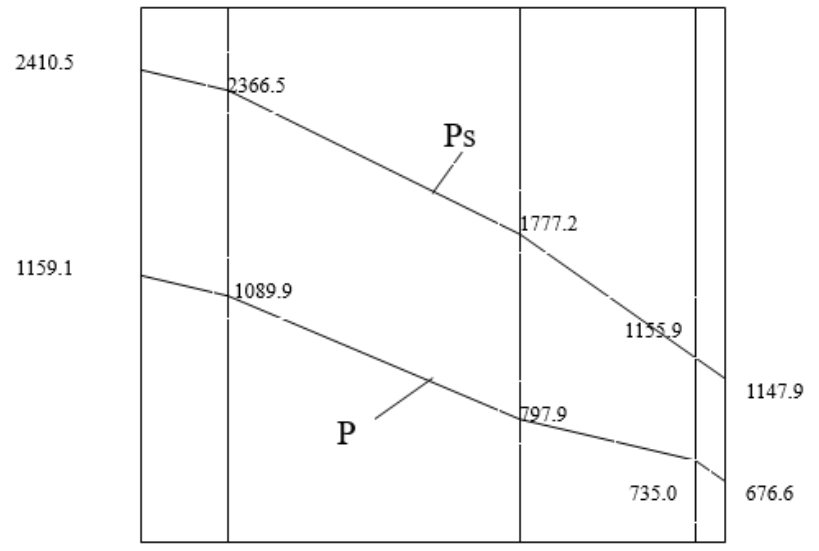

Figure 3. Distribution lines of water vapor partial pressures

\subsection{Relationship between moisture content and calculated/measured temperature}

The minimum temperature at night must be above zero, so that the moisture will not freeze in the voids of wall materials. Otherwise, the measurement accuracy will be affected severely by the ice. Therefore, our thermal experiments were carried out in this late autumn and early winter. On each day, the indoor air-conditioned temperature was maintained stable for 5 hours before the test. Thus, the target walls were considered as in an ideal heat transfer state. The data were collected at around 8p.m., data processing is based on the average values of minimum variance. The thermal calculation was carried out under the assumption of one-dimensional stable heat transfer in these four-layer flat walls.

The experiment lasted ten consecutive sunny days after the continuous rainy weather. The test data interrupted by rainy days were scrapped. In the ten days, there was no significant fluctuation of the weather conditions. The data were measured under the indoor temperature of above $20^{\circ} \mathrm{C}$ and the outdoor temperature at about $6^{\circ} \mathrm{C}$. The slight variation in indoor temperature and humidity did not affect the actual results, because our experiments focus on the relationship between the theoretical and measured values.

The inner and outer surface temperatures of each wall could be read directly by the infrared spot thermometer. The reading was straightforward and convenient. However, this method could not reflect the internal heat transfer accurately as it is easily affected by the environment. Here, the insulation effect was evaluated by the temperature at the interface between the insulation layer and the structure layer of each wall. According to the known conditions of the four-layer flat walls, the values of $\theta_{1}, \theta_{2}, \theta_{3}, \theta_{4}$ and $\theta_{\mathrm{e}}$ were calculated. Among them, $\theta_{3}$ was the calculated value of the said interface:

$\theta_{3}=t i-\frac{R i+R 1+R 2}{R 0}(t i$-te $)$

Simple programs were compiled on the MATLAB for the above condensation inspection and the following thermal temperature calculation and simulation calculation, thereby simplifying the data processing method. 

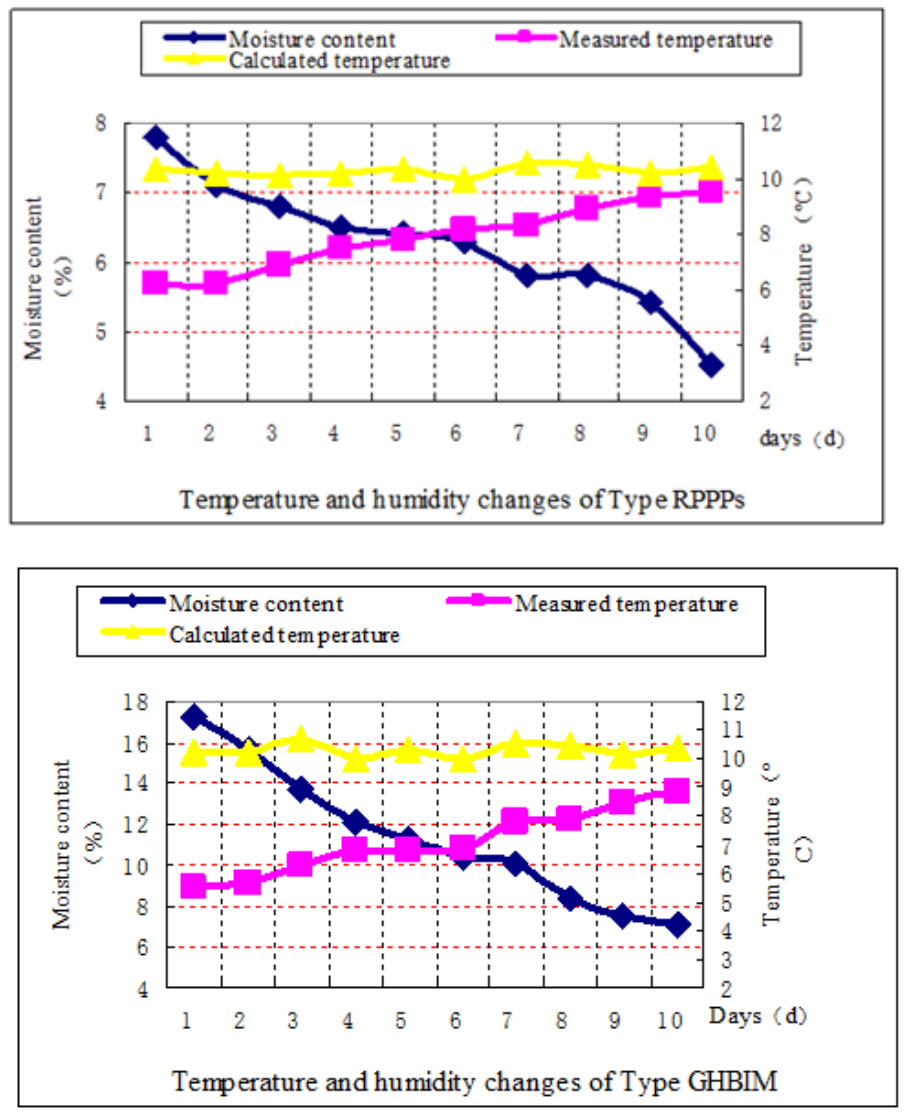

Figure 4. Temperature and humidity changes of Type RPPPs and Type GHBIM

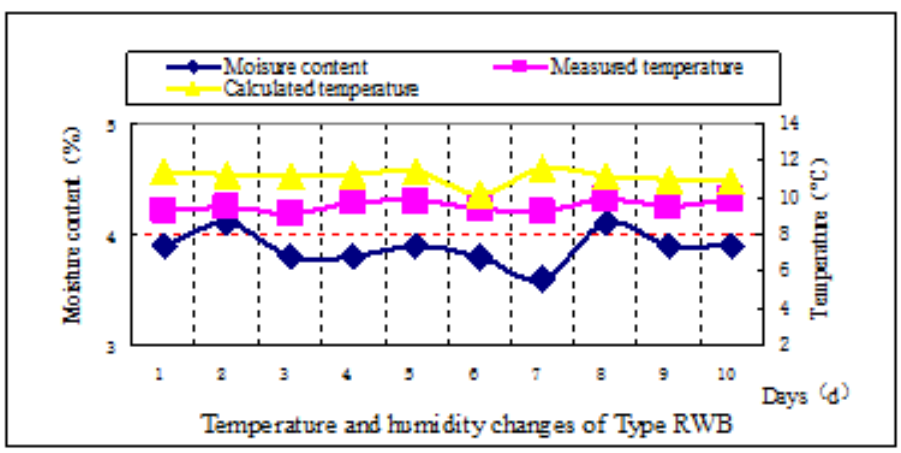

Figure 5. Temperature and humidity changes of Type RWB

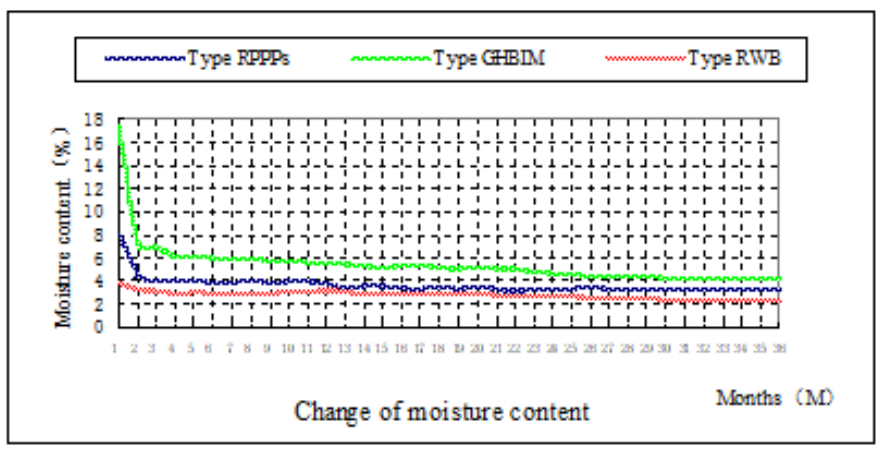

Figure 6. Simulated daily variation of moisture content

\subsection{Analysis of test and calculation results}

Excluding a few outliers, the measured moisture content exhibited an obvious inverse relationship with the corresponding measured temperature (Figure 4). With the evaporation of water, the comprehensive moisture content decreased, leading to the decline in the heat transfer coefficient of the insulation layer. Thus, the heat was better preserved, pushing up the temperature on the interface between the insulation layer and the structure layer.

The measured temperatures of the three ETICS were all below the calculated values. For Type RPPPs and Type GHBIM, this phenomenon could be attributed to the high moisture content after the ten days, the insufficient thickness of the insulation layers, and the substandard thermal parameters of these layers. For Type RWB, the corresponding building was completed only 3 months ago; no thermal insulation and water absorption defects were discovered through infrared scanning, no external moisture was found on the wall surface and the moisture content in the wall was quite stable. In this case, the slight deviation between the measured temperature and the theoretical temperature (Figure 5) was mainly resulted from the incomplete evaporation of the moisture inside the wall. With a high relative humidity, it was impossible to maintain a moisture balance between the inside of the wall and the external environment. Thus, the thermal insulation effect was negatively affected. The deviation is also related to construction quality and material properties.

With a high initial moisture content, the exterior wall with the ETI using GHBIM as the insulation layer material had the largest difference between the measured and calculated values. The relative moisture was always above $90 \%$, as measured by FHA6X6 sensors placed in the cavity of coal gangue sintered hollow brick in the wall structure layer. The result agrees well with the infrared thermogram. The insulation layer of this exterior wall was severely eroded by moisture, failing to achieve the desired thermal insulation effect.

Note that the measuring points were arranged in the areas with severe dampness, as confirmed by the infrared imager, aiming to obtain the clear trends. More measuring points and a longer test period are needed to disclose the actual heat and moisture conditions of the entire building envelope.

\section{COMPARISON WITH SIMULATED ANALYTICAL VALUES}

\subsection{Delphin simulation}

Under the environmental impacts, our experiments only provide short-period data. The illumination conditions were different in the three measurement locations. In addition, the heat transfer mode was simplified as the one-dimensional stable heat transfer. Considering these limitations, the longterm heat and humidity variations were simulated by the heatmoisture coupling software Delphin.

The environmental parameters include the temperature and humidity indoor and outdoor. The short-term indices were configured according to the measured values [10], while the long-term indices were configured as per the local standard meteorological data. The effects of wind and precipitation were not considered in light of the experimental purpose and the local conditions. The solar radiation was measured as $0 \sim 211 \mathrm{~W} / \mathrm{m}^{2}$ by a TBQ-2 total radiation meter.

The property parameters of each material, including the thermal conductivity, specific heat, apparent density, vapor permeability resistance, were determined in reference to the energy-saving design drawings of the actual buildings and the 
Thermal Design Code for Civil Building (GB 50176-93). The boundary conditions and the initial values of each layer were assigned according to the measured values.

The simulation results of the three-year period (Figure 6) shows that the inside of each wall will achieve a moisture balance with the external environment after three years, and will have low overall moisture content. The nine-year period simulation confirmed that the moisture content will remain stable after three years. In fact, the buildings with Type RPPPs and Type GHBIM had been in service for almost 8 years. The unstable moisture content was caused by the structural defects. These results highlight the importance of the construction quality, especially that of the waterproof structure on the outside of the walls.

When the moisture was stable, Type GHBIM had the highest moisture content, while Type RWB had the lowest moisture content. Thus, the GHBIM, as a thermal insulation material, achieved a poor effect when applied on the exterior wall. By contrast, the rock wool can realize excellent thermal insulation effect and durability in the same application scenario.

The simulated results reflected basically the same trend as those of the ten-day experiment, but differed greatly from the latter in numerical values. The difference came from the different settings of the initial humidity. In the software simulation, the initial humidity was configured as the comprehensive humidity of the exterior wall; in the actual measurement, the initial humidity was configured as the local humidity.

\subsection{Comparison with analytical values}

Dr. Liu Xiangwei constructed a heat-air-humidity coupling transfer model for the envelope structures in China's hot summer and cold winter region [11], and applied the model to examine the effects of the moisture transfer in building walls on the thermal properties and energy consumption of the buildings in this region. In this paper, preliminary calculations were conducted by Liu's model. The results turned out as in line with our conclusions in previous sections.

\section{CONCLUSIONS}

1. The moisture content was measured by the capacitive reactance of high-frequency electromagnetic wave sensors. The experimental results prove the convenience and feasibility of this method, and that moisture content can be obtained accurately through instrument calibration.

2. Through infrared scanning, measured moisture content and simulation calculations, it is concluded that the GHBIM has a high moisture content, which will cause deterioration of the wall surface. The deteriorated surface will absorb even more moisture, forming a vicious cycle. The rock wool enjoys a better thermal insulation effect on exterior walls than the GHBIM.

3. No internal condensation was observed in the walls, revealing that the moisture absorption and dampness are attributable to the external water seepage. Under the seepage, the thermal insulation effects of the three ETICS were declined to different degrees.

4. The three ETICS will reach moisture equilibrium after three years of service, as long as the moisture absorption and dampness penetration are avoided.
5. Despite certain deviation, the analytical data reflects consistent trends, and the final results are reliable. Of course, further verification is needed for the modelling and analytical calculations.

\section{ACKNOWLEDGMENT}

This study received financial support from: The Education Department of Anhui Province, China, 2018(Project Title: "Defect Analysis and Durability Study of Typical Exterior Wall Insulation Systems”, KJ2018A0559).

\section{REFERENCES}

[1] Ham Y, Mani M. (2013). Calculating the cost of heating and cooling loss for building diagnostics using EPAR energy performance augmented reality- models. Computing in Civil Engineering 242-249. https://doi.org/10.1061/9780784413029.031

[2] Fazio P, Athienitis K, Marsh C, Rao JW. (1997). Environmental chamber for investigation of building envelope performance. J. Archit. Eng. 3(2): 97-102. https://doi.org/10.1061/(ASCE)1076-0431(1997)3:2(97)

[3] Feng R, Li JP, Li XZ. (2016). Performance study of external wall insulation and a hybrid energy supply system for a rural residential building. Journal of Energy Engineering

142(4). https://doi.org/10.1061/(ASCE)EY.1943-7897.0000366

[4] Barreira E, Freitas VPD. (2007). Evaluation of building materials using infrared thermography. Construction and Building Materials 21: 218-224. https://doi.org/10.1016/j.conbuildmat.2005.06.049

[5] Blaise KK, Magloire KEP, Prosper G. (2018). Thermal performance evaluation of an indirect solar dryer. Instrumentation, Mesure, Métrologie 17(1): 131-151 http://dx.doi.org/10.3166/I2M.17.131-151

[6] Zheng KK, Cho YK, Wang C, Li HR. (2016). Noninvasive residential building envelope $\mathrm{R}$-value measurement method based on inter facial thermal resistance. J. Archit. Eng. 22(4): A4015002. https://doi.org/10.1061/(ASCE)AE.1943-5568.0000182.

[7] Barreira1 E, Vasco P, Freitas D. (2016). Evaluation of surface humidification of exterior insulation and finish systems. J. Perform. Constr. Facil. 30(2): 04015026. https://doi.org/10.1061/(ASCE)CF.1943-5509.0000777

[8] Amir A, Strand RK, Hammann RE, Bhandari MS. (2018). Determination and assessment of optimum internal thermal insulation for masonry walls in historic multifamily buildings. J. Archit. Eng. 24(3): 04018016. https://doi.org/10.1061/(ASCE)AE.1943- 5568.0000320

[9] Liu YF. (2016). Research on the effect of moisture transfer on heat transfer coefficient of building enclosure. Master Dissertation 2016, Xi'an University of Architectural Science and Technology 19-47.

[10] Wang ZH. (2006). Basic research of confirm moisture stability and the infrared method for thermal performance qualitative detection of thermal irregularities in building envelops. Master Dissertation 2006, Harbin University of Technology 25-48.

[11] Liu XW. (2009). Investigation of the coupled heat, air and moisture transport in building walls in hot summer and cold winter zone. Doctoral Dissertation 2009, Hunan University, China 55-89. 